\title{
China asks world to step up on climate
}

\section{BEIJING}

The United Nations Framework Convention on Climate Change (UNFCCC) should set up an inter-government agency to help developing countries tackle climate change, international representatives agreed last week at a meeting in Beijing.

The meeting, convened by the UN and China's National Development and Reform Commission (NDRC), was meant to prepare the ground for next month's summit in Poznań, Poland, where negotiations on a treaty to replace the Kyoto Protocol will kick off. Many believe the very existence of the Beijing conference is a sign that China is seeking a more active role in climate-change talks, in contrast to its previously low profile.

In his opening address, Chinese premier Wen Jiabao said that the developed world needs to move more aggressively to transfer environmentally sound technologies and know-how to other countries, as specified by the UNFCCC. "Many developing countries are undergoing rapid economic growth and urgently need access to clean technologies to make their development environmentally friendly," he said. "There has been no substantial progress so far.”

At a UN conference in Bali last December, developing countries agreed to work harder to reduce greenhouse-gas emissions provided they receive "steady, predictable and reliable" financial and technological support. "It's critical that the details of how this could function are worked out," says Yvo de Boer, executive secretary of the UNFCCC.

In 2001, the convention created an Expert Group on Technology Transfer, but this is largely an advisory committee, with no power to implement its recommendations. "It's a lion without teeth," says William Kojo AgyemangBonsu of Ghana's Environmental Protection Agency.

Under the framework proposed in brainstorming sessions at the Beijing conference, the new inter-government agency would be an independent body able to make and implement decisions and monitor compliance. It would oversee and verify mitigation targets of developing countries, identify barriers to technology transfer, and propose countermeasures. Developed countries would commit to providing it with a steady stream of income for its primary operating budget, possibly supplemented with money from the private sector and other sources.

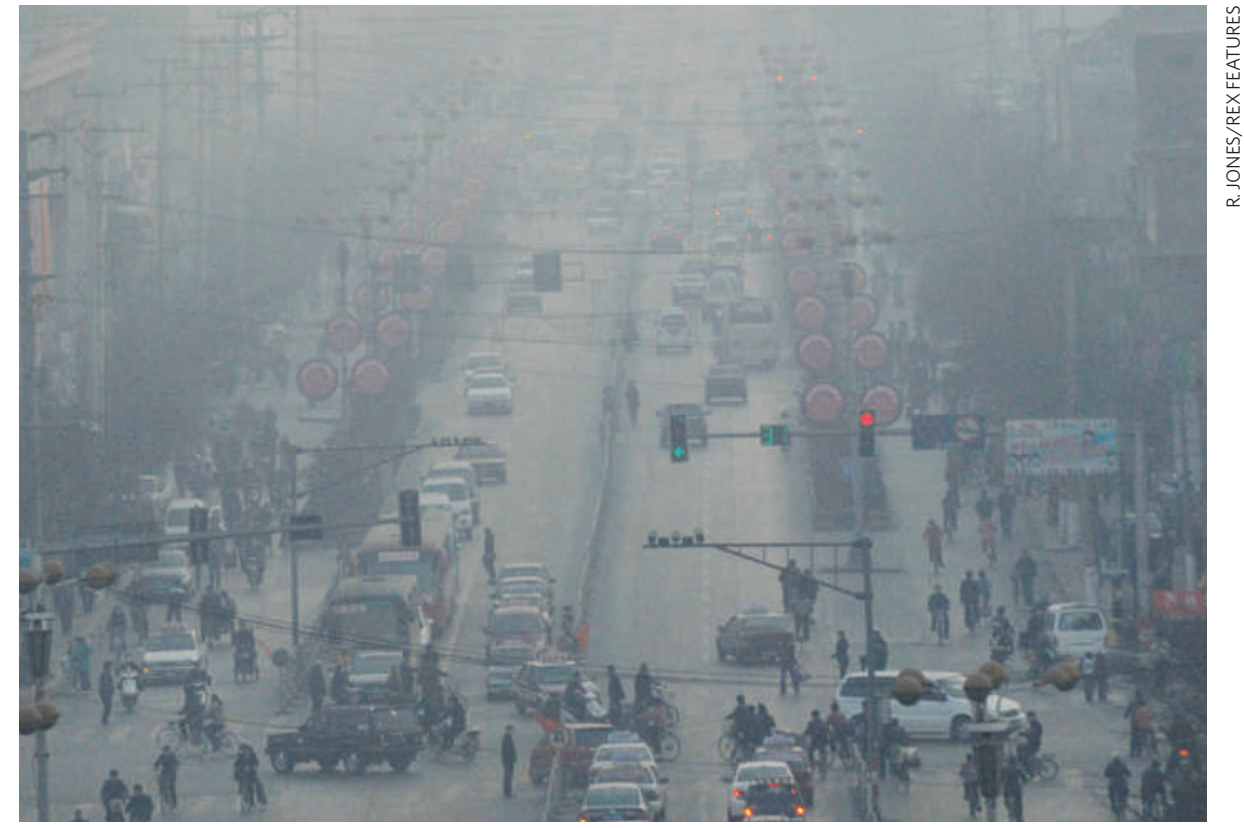

China's greenhouse-gas emissions have caught up with those of the United States.

Last month, Gao Guangsheng, a senior official for climate-change policy at the NDRC, said that developed countries should commit $1 \%$ of their gross domestic product (GDP) to help developing countries tackle climate change. As measured for all the countries in the Organisation for Economic Co-operation and Development, that would clock in at \$284 billion. Ana Maria Kleymeyer of Argentina's secretariat of environment and sustainable development calls that commitment reasonable. "Developed nations have the obligation of clearing up the mess they have made over the past centuries," she says.

Still, many representatives from developed countries say they first want to see developing countries make a firm commitment to emissions-reduction targets. "We are talking about a lot of money here," says Jukka Uosukainen of Finland's environment ministry and chair of the Expert Group on Technology Transfer. "There is no point in transferring low-carbon technologies to a country that is actively promoting a high-carbon economy."

For instance, many would like to see China cap its own greenhouse-gas emissions. On 29 October, China acknowledged for the first time that its greenhouse emissions have caught up with those of the United States and are unlikely to fall any time soon. It declined to give specific figures or say whether these have exceeded US levels, which last year reached 1.6 billion tonnes of carbon emitted from burning fossil fuels.

$\mathrm{Su}$ Wei, director of the climate-change department at the NDRC, says China has invested heavily in mitigation strategies and remains committed to reducing energy consumption and major pollutant discharge per unit of GDP by $20 \%$ and $10 \%$, respectively, from 2005 levels by 2010. "However, it's not time to set an absolute emission cap yet," he says, noting that the emissions level per person in China is only a fifth of that in the United States. And even with such reductions, overall energy consumption would still be higher in 2010 than in 2005 because of the sheer growth of China's economy.

Many questions remain. At the Beijing conference, some discussions covered ways of generating market incentives for technology transfer and reforming the patent system so that poor countries can benefit from technological innovations. Also raised was the fact that market approaches won't solve other neglected areas of development, such as ensuring clean fuel supplies and better agricultural practices.

Conference organizers are putting together a detailed report on overcoming barriers to technology transfer that will be discussed at the Poznań conference.

Jane Qiu 